\title{
Cinco anos de Ceibal: a inclusão digital e suas mudanças nas comunidades fronteiriças
}

\author{
${ }^{1}$ Marcia Maciel, Raquel Machado Leite ${ }^{2}$, Liliana M. Passerino ${ }^{3}$ \\ Programa de Pós-graduação em Educação - Universidade Federal do Rio Grande do \\ Sul- (UFRGS) Porto Alegre - RS - Brasil ${ }^{1}$ \\ CINTED - Universidade Federal do Rio Grande do Sul (UFRGS) \\ Caixa Postal 15.064 - 91.501-970 - Porto Alegre - RS - Brasil ${ }^{3}$ \\ macielmarcia@gmail.com, tpraquelegmail.com, lpasserino@gmail.com
}

\begin{abstract}
This work aims to analyze the digital inclusion project set up in Uruguay, focusing our attention on what think those involved in this project since the arrival of computers in public schools. Our analysis focuses on the testimonies of students, parents and teachers about the impact of the project during the years its existence on the cities of Artigas and Rivera, which are on border with Brazil. The introduction of portable computers in social life provides new possibilities for these people to connect to the world, allowing to analyze the settings of interaction and social inclusion of the protagonists. Introducing Ceibal in school activities made possible the appropriation of innovation, promoting communication spaces, exchange of experiences, cooperation and collaboration between different actors of this scenario: students, families, inspectors, teachers of informatics, teachers of traditional disciplines, technicians, etc.
\end{abstract}

Resumo. Este trabalho visa analisar o projeto de inclusão digital instituído no Uruguai, focando nosso olhar para o que pensam os envolvidos neste projeto desde a chegada dos computadores nas escolas públicas. Nossa análise centra-se em depoimentos de alunos, pais e professores, sobre o impacto do projeto durante os anos de existência nas cidades de Artigas e Rivera, que estão na fronteira com o Brasil. A introdução dos computadores portáteis na vida social oferece novas possibilidades para estas pessoas se conectarem com o mundo, permitindo analisar as configurações de interação e inclusão social dos protagonistas. Introduzir o Ceibal nas atividades escolares tornou possivel a apropriação da inovação, promovendo espaços de comunicação, troca de experiências, cooperação e colaboração entre os diferentes atores deste cenário: alunos, famílias, inspetores, professores de informática, professores de disciplinas tradicionais, técnicos e etc.

\section{Introdução}

O ambiente escolar continua sendo um espaço privilegiado para o conhecimento e intervenções sobre os fenômenos complexos necessários para a convivência e a mudança social. É por isso que o ingresso das TIC's nas escolas se vincula com a alfabetização nas novas linguagens, onde se obtêm novos saberes e a habilitação para novas demandas do mercado de trabalho. Mas a integração pedagógica das TIC's exige 
formar capacidade para a compreensão e participação nesta realidade mediada. Neste sentido a formação sistemática resulta em uma oportunidade para discentes se transformarem tanto em consumidores reflexivos como produtores culturais criativos. É uma oportunidade para desenvolver conhecimentos e habilidades, pois o computador usado de forma correta se torna um grande aliado dos professores no ambiente de aprendizagem, já que as aulas se tornam mais dinâmicas, despertando assim o interesse e aguçando o potencial de criação e investigação dos alunos.

A importância da utilização da tecnologia computacional na área educacional é indiscutível e necessária, seja no sentido pedagógico, seja no sentido social. Não cabe mais à escola preparar o aluno apenas nas habilidades de linguística e lógicomatemática, apresentar o conhecimento dividido em partes, fazer o grande detentor de todo o conhecimento e valorizar apenas a memorização. Hoje, com o novo conceito de inteligência, em que podemos desenvolver as pessoas em suas diversas habilidades, o computador aparece num momento bastante oportuno, inclusive para facilitar $o$ desenvolvimento dessas habilidades. (TAJRA, 2000).

A mudança da função do computador como meio educacional acontece juntamente com um questionamento da função da escola e do papel do professor. A verdadeira função do aparato educacional não deve ser a de ensinar, mas sim a de criar condições de aprendizagem. Isso significa que o professor precisa deixar de ser o repassador de conhecimento - o computador pode fazer isso e o faz tão eficiente quanto professor - e passar a ser o criador de ambientes de aprendizagem e o facilitador do processo de desenvolvimento intelectual do aluno (VALENTE, 1993).

Além disso, o meio social constituído pelos familiares e pessoas de convívio diário destes alunos constitui-se como um local onde os alunos beneficiados pelo projeto de inclusão digital podem deixar aflorar as suas práticas com o uso da ferramenta tecnológica incorporada na sociedade analisada.

Levando em consideração o envolvimento dos pais no processo de acompanhamento, essencial para a promoção do uso adequado e responsável da tecnologia, e os inúmeros aspectos presentes no processo de incorporação da informática pelas escolas, onde a relação entre informática e educação não é imediata, mas mediada, realizamos um levantamento dos cinco anos de Projeto Ceibal, objetivando revelar quais aspectos sociais e educacionais foram explorados, tanto nos espaços escolares como no ambiente familiar, se as técnicas utilizadas colaboraram efetivamente para o avanço do aprendizado, e também para trazer a tona aspectos negativos, caso existam.

\section{Ceibal}

Este projeto espelha-se no programa chamado OLPC (One Laptop for Children) de Nicholas Negroponte, professor do Massachusetts Institute of Technology (MIT), que em 2005 lançou esta organização mundial com o objetivo de distribuir computadores portáteis para a população carente (NEGROPONTE, 2010). O OLPC já foi adotado em diversos países como Argentina, Brasil e Peru. Porém, somente no Uruguai, o projeto teve $100 \%$ da rede pública de ensino contemplada, com a implantação de infraestrutura de rede com possibilidades de acesso a internet em todas as escolas do país. A atribuição do nome do projeto intitulado Ceibal, é um acrônimo de "Conectividade Educativa de Informática Básica para a Aprendizagem Online", e representa sua flor nacional, símbolo do Uruguai: o ceibo. (RIVOIR, 2009); consiste na distribuição de um 
computador portátil para cada aluno e professor, de escolas da rede pública da educação.Os computadores são chamados de XO pelos alunos e comunidade em geral, dando referencia ao projeto de origem da OLPC, já mencionado.

O Ceibal foi instituído pelo governo Uruguaio, para atender toda a população escolar, permitindo um processo contínuo que assegura o acesso às novas tecnologias fundamentalmente para enriquecer os processos pedagógicos que se desenvolvem nas escolas. As ações promovidas se alinham em uma perspectiva que integra as TIC's ao trabalho pedagógico como parte de políticas inclusivas, que tendem a diminuir as brechas educativas, promovendo tanto o uso dessas ferramentas computacionais, como as possibilidades de análise, expressão e participação cidadã que estas viabilizam.

Sua implantação ficou a cargo do Laboratório Tecnológico do Uruguai (LATU) sendo constituída uma comissão política integrada pelos representantes do Conselho Diretivo Central (CODICEN); Conselho de Educação Primária (CEP/ANEP); Administração Nacional das Telecomunicações (ANTEL); Ministério da Educação e Cultura (MEC); AGESIC (Agência para o Governo de Gestão Eletrônica e a Sociedade de Informação e Conhecimento); ANIII (Agencia Nacional de Inovação e Investigação). (UNESCO, 2009), e consiste na distribuição de um computador portátil para cada aluno e professor do primeiro ao sexto ano do ensino primário das escolas públicas do Uruguai.

Considerando os objetivos deste projeto de inclusão digital, foi elaborado um Projeto Pedagógico (Observatics, 2010) que estabelece as linhas de trabalho e neste aspecto seus objetivos são: contribuir para a melhoria da qualidade educativa mediante a integração de tecnologia e atividades escolares, tanto no centro escolar, quanto no núcleo familiar; promover a igualdade de oportunidades para todos os alunos de educação primária que possuem um computador portátil; desenvolver uma cultura colaborativa em quatro linhas: aluno/aluno; aluno/professor; professor/professor e aluno/família/escola; promover a alfabetização e criatividade eletrônica na comunidade pedagógica atendendo aos princípios éticos.

Sua implantação seguiu uma proposta diferenciada a partir de uma estratégia que consistia em entregar os computadores primeiro numa pequena comunidade rural, atendendo, primeiramente, o interior e depois ir avançando por todo o país até chegar a capital, Montevidéu, na última fase, o que começou em 08 de junho de 2009. (RIVOIR, 2009)

\section{Metodologia}

A partir dos estudos desenvolvidos no Uruguai (OBSERVATICS, 2010), é possível inferir um processo de inclusão digital nos alunos. Mas ao observar mais detalhadamente as análises apresentadas nesta pesquisa, verifica-se que os familiares destes alunos fazem uma utilização um tanto tímida deste recurso, tema que será mais explorado ao longo deste artigo. E para que haja a inclusão de fato é necessário o envolvimento de todos neste processo, seja na escola, no meio familiar e na sociedade como um todo.

E assim para esta pesquisa escolhemos um desenho metodológico qualitativo, com a finalidade de analisar um fenômeno que envolve a utilização dos computadores pelos alunos fora do ambiente escolar, tentando encontrar uma forma de melhor compreender as interações sociais estabelecidas. Portanto procurando analisar o fenômeno do Ceibal em termos de sociabilidade em nível de família e comunidade, oportunizando observar e 
entrevistar informantes que forneceram os elementos essenciais para a constituição do nosso trabalho.

O contexto desta observação foram as cidades de Artigas e Rivera, que se situam na região da fronteira do Uruguai com o Brasil e localizam-se distante dos grandes centros, com características bem peculiares, pois possuem uma economia bastante instável oscilando em função de muitos aspectos externos. Nestas comunidades identificamos sujeitos oriundos de escolas públicas localizadas em zona de periferia, que foram beneficiados com o projeto e hoje podem demonstrar suas formas de apropriação e uso desta ferramenta tecnológica.

Na cidade de Rivera partimos de dados de uma pesquisa etnográfica blended $^{1}$ realizada anteriormente e que agora permitiu o retorno a algumas famílias, no total de 10 famílias visitadas, para realizar as entrevistas que compõe este artigo. Já na cidade de Artigas a escolha grupo de sujeitos ocorreu de forma aleatória na comunidade, utilizando o método bola de neve o qual é recomendado quando existem poucos sujeitos de pesquisa ou como em nosso caso o pesquisador é externo a comunidade. O método consiste em localizar poucos sujeitos e solicitar a estes indicadores de possíveis informantes. Esta técnica já foi utilizada em outras pesquisas netnográficas. (MONTARDO; PASSERINO, 2006). Nesta cidade foram entrevistadas mais 10 famílias, procurando entender qual os sentimentos que hoje norteiam a utilização dos computadores nestas famílias. Portanto os dados colhidos no momento de nosso retorno a estas localidades que servem hoje de base para constituição deste artigo.

\section{Reflexões da apropriação da inclusão digital nas cidades fronteiriças}

A relação entre as TIC e a inclusão social, Warschauer (2006) problematiza a causalidade existente entre acesso a computadores/web e inclusão digital a partir de uma pesquisa empírica realizada em países de quatro continentes, inclusive no Brasil.

Ao constatar que projetos que forneciam hardware e software e prestavam pouca atenção aos sistemas social e humano não surtiam resultados satisfatórios quanto à inclusão digital, o autor (2006) propõe que estes sistemas deveriam mudar para que a tecnologia fizesse a diferença. Assim conforme o autor, as TIC não devem ser uma variável exterior ao processo de inclusão, mas devem estar entrelaçadas nos sistemas e nos processos sociais das comunidades a serem contempladas por um projeto dessa natureza. Nesse sentido, promover a inclusão social significa "focalizar na transformação e não na tecnologia" (JARBOE apud WARSCHAUER, 2006, p. 24).

Frente a isso, o autor sistematiza que recursos físicos (computadores e conectividade), recursos digitais (material digital disponível on-line em termos de conteúdo e linguagem), recursos humanos (letramento e educação para utilização da informática e da comunicação on-line) e recursos sociais (estrutura comunitária, institucional e da sociedade que apoiam o acesso às TIC), ao serem empregados como contribuintes para acessar, adaptar e criar conhecimento, favorecendo um círculo virtuoso para ampliar e fomentar novos recursos neste sentido.

4.1 A visão do aluno

No levantamento realizado na cidades de Artigas e Rivera a maioria dos alunos continua utilizando os computadores diariamente na escola (individualmente ou em grupos), na casa de amigos ou outros espaços como praças e locais públicos que possuam acesso à internet sem fio, principalmente para acessar o Portal Institucional do 
Ceibal, onde há recursos disponíveis para estudantes, professores, famílias e ajuda técnica, para caso ocorram problemas com a máquina; também foi narrada a expressiva utilização de blogs, onde os professores disponibilizam conteúdos para estudo e tarefas para a realização em aula ou como atividade extracurricular; há também um intenso uso das redes sociais (sendo o Facebook a rede mais utilizada), programas de conversação instantânea, softwares para a criação de combinações de notas musicais e download de vídeos, músicas e arquivos em geral.

Pudemos observar o grande avanço ocorrido, onde os alunos realmente tomaram posse das ferramentas computacionais, sendo em alguns casos alfabetizados digitalmente e independentes tecnologicamente quase que na sua totalidade.

Apresentamos aqui alguns trechos das entrevistas com os alunos e seus familiares:

"Uso o XO a para estudar, buscar informações em geral, correio eletrônico e como entretenimento para acessar o Facebook, msn, jogar e baixar música. A minha família quase não usa o XO, pois têm medo de estragar. Confesso que minhas notas melhoraram e tenho mais vontade de ir a Escola depois que ganhei o computador". Aluno 12 anos, cidade de Artigas.

“Costumo utilizar o XO para jogar, nos reunimos onde há internet e assim passamos a jogar, algumas vezes eu uso para navegar na internet, fazendo pesquisas.” Aluno 13 anos, cidade de Rivera.

"No inicio, quando recebi o computador, eu usava mais, hoje em dia eu uso mais quando vou a escola, assim se algum professor solicita o uso, caso contrário não estou levando mais na escola. " Aluno 10 anos, cidade de Rivera.

Ao visitar as comunidades estudadas percebem-se grandes disparidades de oportunidades e de utilização dos computadores portáteis que foram distribuídos para todas as crianças, sem distinção. Percebe-se um uso muito mais intenso nos bairros mais carentes e, ao acompanhar esta utilização, percebemos que a comunidade como um todo está organizada e fazendo uma ponte de auxílio para esta utilização, já que existem dentro do próprio projeto de inclusão digital áreas destinadas a dar este apoio diretamente na comunidade - organizações que ajudam a dar sentido a utilização dos computadores por parte dos alunos e familiares.

Assim a rede de apoio ao Ceibal (Rapceibal) participou do inicio do projeto, integrada por mais de seiscentos cidadãos, em sua maioria profissionais, de todo o país, que de forma voluntária, realizaram diversas ações e atividades com o intuito de melhorar a eficiência, fluidez e apropriação do Ceibal por parte de meninos e meninas, professores e a população em geral. Este grupo realizou o aporte inicial colaborando com a distribuição das máquinas, realizando cursos para capacitar os docentes na sua utilização, realizando oficinas e outras ações de caráter operativo em nível local.

Já o projeto flor de ceibo da Universidade da República atua nesta mesma direção, foi criado por um grupo de docentes de diferentes disciplinas busca unir tarefas de extensão, ensino e pesquisa em torno de um trabalho de acompanhamento do Ceibal. $\mathrm{O}$ projeto que começou a funcionar em 2008, através de um convenio assinado com o LATU, contou com vinte e cinco docentes universitários e cerca de trezentos estudantes das mais diversas áreas. Hoje aproximadamente quarenta docentes de diferentes disciplinas estão envolvidos e passam pelas as atividades desenvolvidas centenas de alunos.

Conforme Warschauer (2006) a questão do letramento está ligada a dar sentido a esta utilização. Para o autor o letramento refere-se ao rumo que esta ferramenta precisa tomar dentro da exploração pelos alunos. Ao analisar o que está sendo utilizado pelos 
alunos nas comunidades visitadas, verificamos que eles se encontram bem adaptados ao hardware e software oferecido, e que a equipe que compõe o projeto maior do Ceibal estuda e busca a melhor adaptação dos recursos da máquina com a realidade de cada uma das cidades.

Aqui podemos destacar alguns projetos que vem sendo realizados com o uso das máquinas, dando um real sentido dentro da comunidade na qual se encontra- inserido este equipamento: em uma escola foi criada uma rádio utilizando os recursos do $\mathrm{XO}$ e da internet, que permite o envio diário de informações para os alunos, professores e comunidade escolar, pois a rádio funciona em um turno diferente do horário escolar, o que permite que os alunos possam participar da programação, sendo estes os maiores protagonistas. $\mathrm{Na}$ rádio além das informações referente às atividades vinculadas aos estudos também são apresentadas notícias locais, festejos e o que mais esteja sendo notícia naquela região.

Outra aplicação importante que vem sendo utilizada no Ceibal refere-se ao uso de um determinado programa que foi criado para que as crianças conheçam o seu país e as características de cada departamento. Assim os alunos podem jogar e conhecer através de pistas as peculiaridades de cada um dos departamentos, procurando identificar o nome da cidade conforme as pistas que foram apresentadas. Os programas que envolvem programação também são bastante utilizados, os alunos se envolvem em descobrir novas formas de aplicações e, através de projetos dentro das escolas, estão cada dia mais sendo incentivados a programar e criar aplicativos que um dia possam também ser utilizados pelo projeto.

A utilização destas máquinas é muito variada, em vários casos de alunos entrevistados, observamos que os alunos das séries iniciais estão utilizando bem menos o equipamento do que quando foi entregue a máquina, pois hoje se envolvem- com outros tipos de entretenimento e deixam de lado o computador. Já os alunos maiores de 10 anos fazem um uso mais oportuno do computador, sendo que além de o usarem para o entretenimento o utilizam para questões de aprendizagem, procurando sempre que possível, conectar-se a internet para complementar suas pesquisas. Ao utilizar a internet estes alunos passam a estar na vitrine do mundo e com isso acabam entrando em contato com outras pessoas, fato este que remete ao tema desta pesquisa, que são as redes sociais e permite aos alunos um somatório de ganhos com relação à aprendizagem através de trocas realizadas com alunos com os mesmos recursos, mas em diferentes localidades.

\subsection{A visão da família}

A família dos discentes permanece sem ter interesse em utilizar os computadores dos alunos beneficiados; os pais são os mais arredios, principalmente por receio de não usarem de forma correta e causarem dano ao equipamento, sendo os irmãos mais velhos, que já terminaram os estudos básicos, os usuários regulares dos computadores. $\mathrm{O}$ ambiente familiar serve-se da tecnologia geralmente quando necessita buscar informações sobre saúde (doenças, postos médicos e localização de serviços de urgência), também para fazer uso do correio eletrônico, acessar aos softwares de conversação instantânea e às redes de relacionamento, sendo o Facebook a mais procurada. 
Este foi um dos relatos apresentados por familiares quanto ao uso do computador na atualidade:

"O meu filho aprendeu a usar o computador com os professores, como não temos internet em casa, ele adora ir pra escola para se conectar a rede, quando está em casa ele costuma estudar o material que está arquivado na máquina e também para jogar. Eu quase não utilizo o XO, pois tenho medo de não usar corretando e acabar prejudicar as atividades do meu filho. Já participei de oficinas de informática na escola, oferecida às famílias, aprendi bastante e me senti um pouco mais inserida digitalmente”. Mãe de aluno, cidade de Artigas.

“As minhas filhas usam bastante o computador que veio da escola, uma delas ainda frequenta a escola e a outra que já saiu continua utilizando o computador da irmã, fazem pesquisas na internet e sempre se emprestam. Eu acho muito positivo o uso do computador, como moramos próximo da escola pegamos o sinal em casa e isso facilita a utilização, já que nem precisam sair de casa para utilizar a internet." Mãe de aluna, cidade de Rivera.

A maioria dos familiares entrevistados afirmam que após o início das atividades com o $\mathrm{XO}$, o interesse do filho em estudar e comparecer a escola foi notável e extraordinário, reduzindo consideravelmente os níveis de repetência e estimulando a permanência no ambiente escolar, até nos dias mais frios e chuvosos. Isto tudo favoreceu a construção de contornos de aprendizagem em uma geração que sabe que pode e deve ser capaz de corresponder as exigências de uma sociedade baseada na informação e conhecimento.

\subsection{A visão dos professores}

Os professores são unânimes em destacar as mudanças ocorridas desde o início da implantação do projeto, principalmente quanto à disposição dos alunos na realização das atividades propostas em sala de aula, salientando os jogos educativos e temas sobre a família como os assuntos que despertam maior interessante em aprender, descobrir e investigar, aguçando o potencial criativo dos discentes; também se deve destacar que tanto na escola, como no ambiente doméstico, há um evidente companheirismo entre os colegas de classe, onde se auxiliam mutuamente através da Rede Ceibal, na realização das tarefas propostas pelos professores. Foi apontado que os índices de desenvolvimento da educação aumentaram consideravelmente e a evasão escolar quase foi zerada.

Os docentes afirmaram que há uma forte integração entre aluno, professor e família, já que ele próprio foi o encarregado de fornecer as orientações de utilização do equipamento e o aluno repassou estas ao ambiente familiar, completando um ciclo de alfabetização digital na sociedade. Como nem tudo é perfeito, os pontos negativos citados pelos grupos entrevistados ocorrem principalmente quando há falhas no sistema de internet no momento da realização de uma atividade proposta, onde o trabalho cessa e só pode ser retomado após a normalização da rede.

Embora os professores continuem sendo os maiores incentivadores do uso dos computadores, pois são responsáveis por oferecer ao aluno novas formas de utilização, instigando-o a querer aprender cada dia mais sobre esta máquina e suas possibilidades. A despeito disso, percebemos nas entrevistas que a maioria dos professores, mesmo com o passar do tempo e com novas formas de capacitar-se, alguns ainda estão perdidos ao meio das modernidades, que atualmente fazem parte do cotidiano dos alunos. 
Em alguns casos encontramos professores entusiasmados com o uso, mostrando que os alunos podem ser muito beneficiados com esta rica ferramenta, porém em alguns casos encontramos alunos que somente levam o XO para sala quando solicitado pelo professor, que poucas vezes a utiliza e com isso não incentiva o uso destas máquinas pelos alunos. Percebe-se que isso ocorre muitas vezes com alunos de séries iniciais, estes que nas entrevistas e observações já realizadas demonstram pouco ou nenhum interesse de utilizar os computadores, pois já passou o primeiro impacto da distribuição destas máquinas e agora com o passar do tempo perderam a curiosidade.

\section{Considerações Finais}

E assim com passar do tempo desde a chegada dos computadores nestas localidades torna-se possível refletir um pouco mais sobre o propósito deste projeto de inclusão digital. Percebe-se que é preciso garantir sim o acesso universal as TIC, porém sabemos que nem todos os grupos sociais possuem a mesma facilidade para aproveitar as políticas de acesso generalizado. Assim o Ceibal representa uma chave fundamental para o progresso na conectividade da população do Uruguai, pois está garantindo uma maior universalização do acesso às tecnologias e à conectividade, principalmente para alunos da rede pública de ensino para a qual o projeto destina-se. Desta forma, à medida que este plano avançar poderá incorporar as respectivas famílias e comunidades destes alunos, melhorando assim, a disponibilidade de acesso as tecnologias e a internet neste pais sem distinções de classe sociais.

Através das entrevistas e relatos percebemos que o uso nas famílias ainda é bastante tímido, sendo que nos relatos dos alunos poucos apontam para uma utilização mais intensa. Com grande frequência, observa-se por suas falas que os seus familiares não fazem o uso dos computadores por vários motivos, um deles seria a falta de oportunidade das próprias crianças, pois estas não incentivam nem orientam o uso por parte de seus familiares. Ao conversar com os pais percebemos que alguns têm interesse, mas acreditam que as máquinas são de propriedade dos filhos e que assim foram projetadas especificamente para as crianças, não lhes cabendo o direito de uso.

Percebe-se, outrossim, que a comunidade como já encontra-se bastante modificada desde a chegada dos computadores, pois estes passaram a desenhar um novo cenário de vida cotidiana nesta localidade. Evidenciou-se no inicio do projeto um forte entusiasmo por parte das famílias e, principalmente, das crianças, com a chegada dos computadores e agora se percebe que estes já se adaptaram ao seu uso e que já registram novas práticas que compõem este novo cenário da comunidade. Observam-se crianças sentadas nas calçadas fazendo o uso dos computadores, ao sair da escola pode-se visualizar alunos caminhando com os computadores abertos buscando conectar-se através da rede da escola, pais que ao buscar seus filhos na escola o levam junto a mochila do aluno, como mais uma ferramenta que pode ser usada em sala de aula. $\mathrm{O}$ cenário mudou, as possibilidades são outras e tendem a cada dia mais avançar nesta exploração.

Outro eixo pontuado por Warschauer (2006) em seus estudos e que procuramos contemplar nesta pesquisa, refere-se à conectividade, o autor afirma que não basta oferecer máquinas, é preciso que estas tenham a possibilidade real de acesso à internet. No inicio deste projeto várias adaptações precisaram ser realizadas nas escolas, instalações físicas e muitos recursos foram estudados para serem aplicados em cada 
realidade encontrada. Com isso, foi possível oferecer conectividade em uma grande maioria das escolas, sendo que atualmente existem poucas que ainda não possuem energia elétrica e que por isso não estão equipadas com a internet. Contudo já vem sendo estudado a possibilidade de se aplicar nestes casos placas solares, permitindo assim, a chegada da energia para as escolas para posteriormente serem adaptadas uma forma de acesso a internet. Na maioria das escolas de Rivera e Artigas há o acesso via internet sem fio, nas escolas e em suas proximidades os alunos tem a possibilidade de se conectar utilizando a rede Ceibal de conectividade. É muito frequente ver alunos em frente das escolas buscando acomodar-se para ali terem acesso à internet e poder viajar um pouco nestas novas experiências. Ao questionar sobre que tipo de atividade que realizam com o computador quando tem a possibilidade de conectividade surgem inúmeras alternativas de entretenimento e aprendizagem, fazendo com que se reforce a idéia inicial de Warschauer (2006), na qual afirma a necessidade de conexão nestas máquinas, permitindo o uso mais adequado e rico para estes alunos.

O letramento e desenvolvimento humano estão sendo modificados ao longo dos dias, já que o programa foi implantado desde o início de 2008 nas cidades citadas, e percebe-se a cada dia novas práticas na sociedade, as quais se originam da exploração destas máquinas pela comunidade. Houve uma grande preocupação dos envolvidos em oferecer, desde o inicio, equipamentos adequados para as crianças. A opção pelo computador portátil oriundo do projeto maior OLPC se deu devido as características destas máquinas, as quais foram realmente adaptadas para utilização das crianças. Porém, como já foi mencionado anteriormente, isto não garante um uso de qualidade pelas crianças envolvidas e sim se soma a uma série de outros fatores também importantes que tornam o uso realmente adequado.

A capacitação dos professores, item que compõe o eixo letramento, está hoje focada em dar um apoio maior para estes que são responsáveis pelo controle em sala de aula destas máquinas. Atualmente os professores, além de receber a capacitação na capital do Uruguai, recebem ainda apoio na página do próprio projeto. Nesta página, o professor que possui cadastro pode se atualizar, bem como testar novos softwares que podem ser baixados e trabalhados posteriormente com seus alunos. Portanto, percebe-se um crescimento por parte dos envolvidos neste processo, pois hoje, além de o professor estar se capacitando tem a possibilidade de se comprometer a contribuir disseminando o uso cada vez maior de novos aplicativos entre seus alunos, fortalecendo os incentivos recebidos para este projeto.

Por analisar o fenômeno desencadeado no Ceibal, que pretende promover o acesso a computadores e Internet para a população de modo geral, atingindo também as classes menos favorecidas, percebemos a importância de analisar a implantação de uma política educacional que extrapola os muros da escola e se mostra como um grande desafio, uma vez que esta análise irá exigir uma proposta metodológica que permite "re-construir" caminhos, percorrer galhos e recolher frutos tentando "mapear" uma situação que deu origem, mas que se modificou no mesmo instante que a mapeamos.

Com isso é possível imaginar que futuramente o ritmo deste projeto deverá se expandir, possibilitando assim, colocar o Uruguai em uma posição de um país que mais rapidamente instrumentalizou seus alunos em termos mundiais, tamanha a magnitude deste projeto. Porém é necessário realizar um acompanhamento intenso do processo de integração dos computadores ao currículo de aula, favorecendo que o uso deste novo 
recurso esteja de acordo com o planejamento pedagógico e educativo das escolas, para então serem utilizados, apropriando o recurso tecnológico a serviço dos próprios interesses educativos.

Para tanto é necessário incentivar a reflexão que possa favorecer a integração curricular das TIC com o andamento deste projeto, trazendo grandes consequências em várias dimensões do sistema educativo do Uruguai. Além dos aspectos educativos, não podemos esquecer dos fatores sociais que podem e devem ser transformados através da utilização adequada destas ferramentas, e isso somente é garantido através de uma identificação coerente do local e necessidades nos quais encontram-se inseridos esses alunos.

\section{Referencias Bibliográficas}

BEZ, Marta Rosecler, Vicari, Rosa Projeto um Computador por Aluno - UCA Formação Brasil. Sbie 2010: Joao Pessoa.

NEGROPONTE, Nicholas. (2010) “One Laptop per Child”. Disponível em: http://www.laptop.org/en/. Acesso 08/2012.

TAJRA, Sanmia Feitosa. Informática na educação - Novas ferramentas pedagógicas para o professor da atualidade. Editora Érica, 2000.

UNESCO, En El Camino Del Plan Ceibal: Referencias para padres y educadores, Uruguai, 2009.

UNESCO, Ceibal en la Sociedad del Siglo XXI: referencias para padres y educadores. Uruguai, 2009.

UNESCO. (2010) En el Camino del Plan CEIBAL. ISBN 978-92-9089-135-2. Montevideo, Uruguay.

VALENTE, José Armando. Análise dos diferentes tipos de software usados na educação. In: Salto para o futuro: TV e informática na educação. Secretaria de Educação a Distância. Brasília: Ministério da Educação, 1998. 112 p. Série de Estudos Educação a Distância.

XAVIER, Karine. Inclusão digital nas escolas públicas: Uma questão social. In: Revista Brasileira de Tecnologia Educacional. Ano XXXIV N 170/171, pg. 47- 54, 2005. 